Laboratorio de Arte,4-1991 http://dx.doi.org/10.12795/LA.1991.i04.13

\title{
NOTAS BIOGRÁFICAS DEL PINTOR SEVILLANO JOSÉ RICO CEJUDO (1864-1939)
}

\author{
por Gerardo Pérez Calero
}

\begin{abstract}
El presente artículo muestra el estudio de los más sobresalientes aspectos de la biografía inédita del interesante pintor sevillano José Rico Cejudo (1864-1939), deteniéndose especialmente en aquellas noticias que por su valor artístico más interesan a los estudiosos de esta etapa deb arte sevillano.

Su autor se entretiene en analizar junto a noticias puntuales de la biografía de Rico Cejudo en su entorno personal y familiar, otras que hacen referencia a las aficiones literarias y musicales populares del pintor, tales como su vertiente en el campo del folklore musical, especialmente del llamado "cante hondo", en el que llegó a destacar sobre todo como compositor de coplas populares.
\end{abstract}

This article is a study of the most notable aspects of the life of the little-known Seville artist José Rico Cejudo (1864-1939), paying special attention to elements whose artistic value makes them interesting to students of this period of Sevillian art.

Together with details of the biography of Rico Cejudo and his personal and family environment, the author refers to the painter's interest in literature and popular music, including the field of folk music, especially "cante hondo", and his talent as a composer of popular lyrics.

Consciente del valor que las biografías tienen en el estudio de los artistas y sus obras, paso a dar cuenta del perfil personal de tan interesante pintor sevillano, representante de la estética regionalista y cuya personalidad humana justificaría de por sí este trabajo.

José de la Santísima Trinidad Ruperto Rico y Cejudo nació en Sevilla el día 27 de marzo de 1864, en la calle de San Pablo número 52, siendo bautizado once 
días después en la iglesia parroquial de Santa María Magdalena, templo en el que también recibieron el sacramento Murillo y Gonzalo Bilbao ${ }^{1}$.

Su padre, Manuel Rico, era un modesto fabricante de sillas en la ciudad, de la que era natural, y su madre, Ana Cejudo, había nacido en Osuna. Sus abuelos paternos sevillanos, y los maternos oriundos de Écija y Osuna.

Tras los estudios primarios y entrada la década de los ochenta, José ingresa en la Escuela de Bellas Artes de Sevilla, dependiente entonces de la Academia Provincial. Allí recibe enseñanzas de prestigiosos profesores y artistas, entre ellos Eduardo Cano, Manuel Wsel, García Ramos, etc. Su aprovechamiento docente es ratificado por su buen expediente académico y la consecución de alguna recompensa como el premio en los estudios de Antiguo, Sección de Cabezas, que se le otorga el 7 de octubre de 1883 en la Junta general pública de la Corporación ${ }^{2}$.

Como pintor en ciernes, Rico Cejudo ejercía su oficio con interés e ilusión, no desaprovechando ocasión que se le presentase para dar a conocer sus primeros cuadros ejecutados con verdadera vocación y entrega. Una de sus primeras obras, El niño de la paloma (paradero actual desconocido), obtuvo un premio de 250 Ptas. en un concurso convocado por el Conde de Casa Galindo en 1887.

$\mathrm{Al}$ año siguiente, contando 23 de edad, fue pensionado por el Ayuntamiento de Sevilla para seguir sus estudios en Roma, en donde permanecería siete años. Su estancia italiana fue muy importante para su formación, como él mismo reconocerá en 1918, al decir: “... Creo de necesidad que se visite y se estudie detenidamente el tesoro artístico de Italia, cuna en todos los tiempos del arte mundial." 3. Allí entra en contacto con el rico ambiente existente en la Ciudad Eterna en torno a la Escuela de Bellas Artes española y al círculo de artistas que de alguna manera renuevan su formación al calor del ambiente neorromántico que Fortuny y su escuela preciosista habían creado, y del que José Villegas era uno de los artistas más prestigiosos. Además, pintores sevillanos como Mattoni, Gonzalo Bilbao y otros muchos reciben entonces una precoz renovación en sus estilos aún no definidos y algo anquilosados, lo que se traducirá en la aclaración de sus paletas, que se tornan brillantes y coloristas. Fruto de su estancia en Italia son obras de ambiente clásico pese a que su veta hispánica y andaluza sigue presente en este período. De ello se hace eco la prensa gráfica española contemporánea. Una publicación de la época decía al respecto: "En la ya numerosa lista de artistas españoles que en la ciudad eterna honran a la madre patria por la valía

1. Iglesia parroquial de la Magdalena de Sevilla. Libro 42 de bautismo, folio 52.

2. MURO OREJÓN, A.: Apuntes para la historia de la Academia de Bellas Artes de Sevilla. Sevilla, 1961, p. 112.

3. "El Liberal", Sevilla, 8-6-1918. 
e importancia de sus obras o bien por los asuntos de carácter nacional que en ellos representan, preciso es continuar el nombre del joven pensionado Sr. Rico, puesto que en cada una de sus producciones halla medios para tributar un cariñoso recuerdo a su ciudad natal y justificar la honrosa distinción que de ella mereció. El bonito cuadro -Una boda en Sevilla- de carácter y asunto genuinamente español, ha figurado dignamente en la última exposición de Munich, en donde fue adquirido para formar parte de una de las mejores galerías particulares que existen en la capital de Baviera" 4.

Estando en Roma fue propuesto por el embajador de España al Gobierno de su majestad para la concesión de la Cruz de Isabel la Católica, libre de gastos, por sus trabajos pictóricos como pensionado ${ }^{5}$.

En 1896 Rico Cejudo, a sus treinta y dos años de edad, ya en España, formado como pintor y con cierto nombre entre los artistas sevillanos, es visitado en su estudio por Eugenio Sedano, quien hace una interesante y amena descripción del ambiente que encuentra en su taller: “... Aquel estudio era, no el sosegado y tranquilo rincón donde el arte se inspira buscando en la soledad la idea; sí el fumadero de varios amigos que reían alborotados, permitiéndose bromitas con los modelos y poniendo en guardia al visitante novato." Acerca de la personalidad del artista, dice el escritor: "culto, sin pedantería, modesto y activo, Rico trabaja más para los suyos que para él. De aquel cerebro impresionable y revoltoso, siempre pensando algo que proporcione quehacer a su dueño, no salen extravagancias del genio, ni locuras de atolondrado" 6 .

Por entonces, y para ayudarse económicamente, imparte clases de Dibujo en la Academia Politécnica sevillana para la preparación militar de ingenieros y arquitectos.

Entretanto, no pierde oportunidad para dar a conocer su obra, siempre atractiva, que la crítica trata en general con ponderación e interés, haciendo hincapié en la humanidad de su estilo pictórico por lo que de popular tiene. Participa con éxito en la exposición de Sevilla de 1897 y en las regionales de Granada y Málaga de 1901 y 1902 respectivamente, consiguiendo importantes recompensas con cuadros, que, al decir de la crítica, constituyen "producciones de fácil salida, inclinándose por la tortuosa trocha del arte chico" 7 .

Su faceta docente se materializa en el nombramiento de Ayudante meritorio de la asignatura de la Sección Artística de la Escuela de Artes y Oficios Artísti-

4. "La ilustración artística", Barcelona, 21-11-1898.

5. Escuela de Artes Aplicadas y Oficios Artísticos de Sevilla. Archivo de profesorado. Expediente de Rico Cejudo. S/d. s/p.

6. SEDANO, Eugenio: Estudio de estudio. Sevilla, 1896, p. 23.

7. Sebastián Alonso. Exposición de Bellas Artes de Sevilla de 1897, pp. 69-74. 
cos y Bellas Artes de Sevilla para el curso académico 1905/6 en 18 de noviembre de 1905, desempeñando este cargo bajo la dirección del eminente pintor y catedrático Gonzalo Bilbao, a la sazón numerario de Composición decorativa ${ }^{8}$.

Su entrada en la docencia, en la que permanecerá hasta su jubilación reglamentaria a los setenta años, viene acompañada por la pronta incorporación a la Real Academia de Bellas Artes hispalense, que en sesión de 26 de diciembre de 1907 le nombra miembro numerario en la plaza del que también había sido pintor muy destacado, Emilio Sánchez Perrier, muerto tres meses antes ${ }^{9}$.

La actividad de Rico Cejudo como artista es incesante en esta época. Su estudio, instalado entonces en su casa de la calle Cañaverería número 23 , mantenía un ritmo de trabajo casi febril ya que sus cuadros de fácil venta pronto conseguían comprador, a veces extranjeros que veían en ellos la representación de la genuina idiosincrasia andaluza, actualización muchas veces de las viejas estampas pintorescas y costumbristas. De vez en cuando, el pintor acudía a las exposiciones públicas en Sevilla o Madrid, e incluso lejos de su tierra; así, a México en 1910, en donde consigue medalla única ${ }^{10}$.

Desde los primeros años del siglo se va haciendo patente en Sevilla, como centro artístico y cultural importante, las ideas y teorías regionalistas que arrastran con particular entusiasmo a creadores y pensadores que ven en este movimiento ideológico la renovación y el resurgimiento de los ideales historicistas de la tierra y las gentes de Andalucía. Pintores como Gonzalo Bilbao, de la misma generación que Rico Cejudo, supieron captar con particular sensibilidad la expresión del alma popular que el regionalismo preconizaba como algo genuino de la tierra. La obra de ambos pintores, fiel reflejo del ideal andaluz, lleva al mencionado movimiento a su máxima expresión pictórica en torno a 1915, fecha en la que Bilbao recibe el clamor popular por su cuadro Las cigarreras en la fábrica de Tabacos de Sevilla ", y año también en el que Rico Cejudo presenta varios cuadros de asuntos y costumbres sevillanos en la Exposición de Bellas Artes hispalense. Igualmente en el certamen del año siguiente del Ateneo, en el que el crítico Pedro de San Ginés veía "un renacimiento de las artes andaluzas" 12. Cuelga tres cuadros, hechos, al decir del mencionado crítico, "con la vivacidad de ejecución que le caracteriza. De las tres obras, la mejor es, sin duda -añadía-, El aguador". En esta misma línea de arte regionalista hay que situar el cartel anunciador de las fiestas primaverales de Sevilla con la representación, muy

8. Vid nota 4 .

9. MURO OREJÓN, A.: Op. cit., p. 82.

10. CUENCA, Fco.: Museo de Pintores y Escultores andaluces. La Habana, 1923, p. 310.

11. Véase mi libro Gonzalo Bilbao. El pintor de las cigarreras. Madrid, 1989, pp. 28-31 y 74.

12. "Artistas sevillanos y Exposición de bellas artes", Rev. "Bética". Sevilla, 1916. 
original en el tema, de los gitanos que en caravana se acercan atraídos por el embrujo de la Feria de abril ${ }^{13}$.

En 1918 ( 9 de enero) es nombrado Profesor de Entrada transitorio en la Sección Artística de la Escuela de Artes y Oficios Artísticos y Bellas Artes a propuesta de la dirección del centro y por orden de la Subsecretaría correspondiente del Ministerio ${ }^{14}$.

Meses después, Rico Cejudo, dando rienda suelta a sus aficiones literarias, publica uno de sus primeros trabajos en la prensa local, abogando fervientemente por el restablecimiento de las pensiones que el Ayuntamiento de la ciudad otorgaba a artistas jóvenes que reunían condiciones para seguir sus estudios en España y en el extranjero. Aprovecha, al recordar su época de pensionado por la corporación municipal, para exponer a modo de experiencias y con evidente talante artístico liberal y progresista una serie de sugerencias. Entre ellas apunta: “... una larga residencia en una misma localidad lleva fácilmente al estancamiento y aún al amaneramiento que todavía es peor. Creo de necesidad que se visite y se estudie detenidamente el tesoro artístico de Italia, cuna en todos los tiempos del arte mundial, y cada uno en su manera de ser pueda detenerse donde crea. conveniente más o menos tiempo sin que la pensión le obligue a tener residencia fija, pues como cada artista es un temperamento distinto, debe tener amplitud y libertad absolutas para manifestarse en sus producciones tal y cual sea su manera de sentir.

Siempre cabe -añade el pintor- la restricción y garantía de la entidad protectora de obligar al pensionado a presentar anualmente sus trabajos para atestiguar su laboriosidad y adelantos.

Estamos en una época - continúa- de renovación en todos los órdenes de la vida y aunque se imponen moldes nuevos en el convivir moderno, es de necesidad no dejar a un lado la protección a las bellas artes, refinamiento de la cultura en los pueblos y en Sevilla desde tiempo inmemorial y con verdadero orgullo podemos vanagloriarnos de tener el historial más glorioso en artes que pueda ostentar ninguna otra población española".

Termina su artículo con un lírico canto de esperanza y seguridad en el futuro, con estas palabras: "Debo mi carrera a la generosidad de nuestro municipio, al que estaré agradecido lo que dure mi vida y como me precio de ser altruista como el que más, me alegraré en el alma sean un hecho muy pronto los justos deseos de los jóvenes artistas sevillanos entre los que conozco uno o varios que

13. Sobre su labor como cartelista, véase: MATEO DE LOS SANTOS PÉREZ, G.: Un siglo de carteles festivoreligiosos en Sevilla (1881-1987). Sevilla, 1988.

14. Archivo Central del Ministerio de Educación y Ciencia. Alcalá de Henares. Expediente de Rico Cejudo, legajo 13.606/8. 
con protección a tiempo darán seguramente días de gloria a nuestra Sevilla con el producto de su talento" 15.

Como cualidad sobresaliente del pintor destaca su desvelo por los jóvenes artistas sevillanos y especialmente sus alumnos de la Escuela. Hombre de alma buena y afable carácter, compartía con ellos los momentos importantes de su vida, contándose por algunos de sus discípulos multitud de anécdotas ocurridas en sus clases y fuera de ellas. En este sentido, Antonio Illanes, al recordarle con motivo del primer centenario de su nacimiento, evoca su falta de sentido práctico del ahorro por lo que, según dice, "siempre andaba desmejoradillo de la blanca. Pero un día -prosigue el escultor- entró en la clase alterado y, dirigiéndose a todos nosotros, nos dijo triunfante y enternecedor: ¡Venid a mis brazos y felicitadme, hijos míos! ¡Siete mil duros como siete mil soles me han dado unos indianos para que les pinte dos cuadros! ¡Esto es El Dorado fabuloso! ¡Menudo veraneo me espera con mi medio almud (su mujer)! Nosotros -añade Illanes-, acostumbrados a sus regocijantes fantasías no lo creímos. Pero era verdad. Sucedió que unos americanos llegaron a nuestra ciudad para hacer el encargo de unas copias de los grandes lienzos que se hallan en el Museo y representan "Las postrimerías de San Fernando", de Mattoni, y "La primera Misa", de Alcázar Tejedor. Toparon con Rico, y para hacer caer a su favor el platillo de la áurea balanza, les organizó en su taller una "juerga flamenca" en la que cantó por lo "jondo" soleares, polos y cañas, que lo hacía con singular destreza y con sabores de otros tiempo" ${ }^{16}$. (Vid fotografía).

El mismo Illanes trae a colación también su sencillez y espontaneidad, con trato amable y a veces burlón para con todo el que le trataba; así, comenta cómo en cierta ocasión que su casero le apremiaba en el pago de la renta so pena de desahucio, le respondió: “¡A mí! ¡A Don José Rico Cejudo -barbulló coléricovenirme con esa embajada! ¡Yo que estoy casi al corriente! ¡Qué sólo debo dos años! ¡Es inaudito! ¡Qué insolencia!... ${ }^{17}$.

Cuenta, por último, el escultor Illanes cómo hacía en una ocasión un paisaje lleno de luz solar en un día nubladísimo y, ante el asombro de los amigos que lo contemplaban, aclaró espontáneo e imperturbable: ¡Es que así entono mejor las sombras! ${ }^{18}$.

En 1920 colabora como ilustrador gráfico en el libro Quien no vio Sevilla..., editado por el Ayuntamiento de la ciudad sobre temas y leyendas locales, y en el que participan también destacados escritores y pintores hispalenses. Viene a ser como un cántico a su ciudad natal en el que pone de manifiesto con claros acentos líricos su amor por ella.

\footnotetext{
15. "El Liberal", Sevilla 8-6-1918

16. “ABC", Sevilla, 19-3-1964.

17. Idem.

18. Idem.
} 
Por entonces, además de pintar escribe, llegando a componer varias novelas, entre ellas las tituladas "Las rosas de la amargura" y "María del Carmen", de la biblioteca "La novela del día". También colabora en temas de difusión científica y cultural mediante artículos de divulgación arqueológica y artística en los que hace gala de su vasta erudición. La prensa local inserta muchos de ellos. También compone poesías que luego recita en reuniones y tertulias públicas y privadas.

Al mismo tiempo, sus cuadros van siendo cada vez más conocidos dentro y fuera de España, adquiriendo importante cotización sobre todo en el mercado americano. En la Exposición de Buenos Aires de 1921 se exhibieron varios trípticos con temas y ambientes sevillanos (Palacio de las Dueñas, Jardín de Capuchinos, etc.), que fueron muy ponderados por la crítica local y española.

Mientras tanto, y por Real Orden de 30 de septiembre de este año, desempeña una plaza de Profesor Auxiliar de la Sección Artística del Grupo primero de Dibujo Artístico de Sevilla, en virtud de concurso de acceso en turno transitorio entre ayudantes meritorios. Mas su faceta docente quedará definitivamente consagrada con el nombramiento de Profesor Auxiliar numerario de Dibujo Artístico en 30 de agosto de $1923^{19}$.

El amor de Rico Cejudo por las costumbres y tradiciones de su tierra, como antes se indicó, no solo se plasma plásticamente en cuadros y colaboraciones gráficas, sino también en la composición de coplas que él mismo entonaba, muchas de las cuales recogió en su libro "Alma andaluza", publicado en 1925 y dado a conocer públicamente en el Ateneo de la ciudad en 16 de mayo de ese año ${ }^{20}$. Constituye una colección completa de cantos inspirados en el espíritu de la región y presentados bajo la graciosa forma del habla popular:

Seguidillas de baile

"Llegué a la puertecita de tu cortijo

¡Qué fresca está el agua de tu botijo!

Me supo a mieles como saben las cosas a quien bien quiere."

\section{Soleares}

"Vendiendo las canastillas alegra toita la calle lo que yo siento por ella eso no le importa a naide."

\section{Saetas}

"La luna estaba alumbrando ar Divino Redentó que agobiao por las penas nuestras curpas redimió..."

19. Vid nota 14.

20. "El Liberal", Sevilla, 17-5-1925. 
Malagueñas

"Malagueñito

que juró que me quería

me fartó en un juramento

y acabó con mi alegría."

Cañas y polos

"Cuando me entro en la iglesia le pido a toitos los santos que no dejes mi cariño que veo estas orviando."

Seguidillas gitanas

“iPorque me martratan si no he jecho na;

que diga er borrico

si no fue su gusto

er venirse etras!"

\section{Carceleras}

"Triste me encuentro en la carce por causa de una mujé que por defendé su honra la perdición me busqué."

\section{Campanilleros}

"De la iglesia de Santa Lucía salía el Rosario, a eso de las dos, y en la puerta un pobre lisiado en un gran lamento, imploraba a Dios. ¿Y qué sucedió?

Que entonando el avemaría se puso tan bueno que cogió un faró."

\section{Columpio}

"Eres chiquita y bonita, y tu cara es un jazmín, tu cuerpecito es rosal de los de pitiminí..."

\section{Caleseras}

"Anda caleserito arrea ligero que espera la paloma que tanto quiero pa i a los toros que alterna Chiclanero con er Manolo."

\section{Serranas}

"Por la sierra adelante va una pastora, el ídolo del valle que bien se adora, lleva las flores pa el altar de la Virgen de los Dolores."

\section{Machos}

"Cuando voy por los campos de Grazalema montao en mi mulilla campanillera voy yo pensando robar tus ojos negros de contrabando." 
En 25 de mayo de 1928, a propuesta de la Escuela de Artes Aplicadas, es nombrado para desempeñar la cátedra vacante de Perspectiva, Paisaje y Acuarela, y dos años después, por Real Orden de 8 de octubre, se le encarga de la cátedra Especial de Colorido, Composición y Procedimientos pictóricos. Posteriormente, por orden de la Dirección General de Bellas Artes de 31 de enero de 1931, pasa a ocupar la cátedra vacante de Dibujo Artístico; desempeñando de nuevo la de Colorido y Composición al final de este mismo año, pero cesando en 18 de julio de 1936 por sorprenderle el Movimiento en Madrid, en donde se hallaba de vacaciones ${ }^{21}$.

A pesar de la aparente relevancia de los puestos antes mencionados, sus bajas retribuciones le obligan a solicitar la simultaneidad en otros cometidos docentes con objeto de aumentar sus derechos pasivos, pues se hallaba próxima su jubilación. En ese sentido, y en 20 de agosto de 1932, había solicitado tomar parte en el concurso para proveer la plaza de Dibujo Artístico en el Instituto de Segunda Enseñanza, recién creado en Sevilla; y con posterioridad, en 1934, también solicita su participación en el concurso para proveer entre profesores auxiliares la cátedra de dibujo artístico de la Escuela de Artes y Oficios Artísticos de Toledo ${ }^{22}$. En ambos casos no logra sus objetivos, consiguiendo sin embargo, y pese a haber alcanzado la edad de jubilación en este mismo año de 1934, la declaración de "apto para la continuación en el servicio activo de la enseñanza" por el Ministerio de Instrucción Pública y Bellas Artes, con fecha 17 de abril, lo que supone desde luego un alivio tanto en su situación económica momentánea como en sus derechos pasivos próximos.

Por otro lado, Rico Cejudo ostenta simultáneamente otros cargos honoríficos en corporaciones e instituciones sevillanas vinculadas con su actividad; así, vocal del Patronato del Museo Provincial de Bellas Artes y Académico y Consiliario de la de Santa Isabel de Hungría, ambos desde 1934.

Con setenta años cumplidos el pintor tiene más tiempo para dedicarse amorosamente a sus aficiones literarias. En este sentido, publica en 3 de julio de 1935 un interesante trabajo sobre "Ideas críticas del arte pictórico", correspondiente a la serie "Papeletas de Arte" que edita la Academia de Bellas Artes de Sevilla. En él vierte muchos de sus criterios artísticos acerca de un oficio que conocía bien y al que consagró toda su vida.

Este último año lo pasa en su ciudad natal preparándose con vista a su participación en la Exposición Nacional de Bellas Artes de 1936. Esta se inaugura el 4 de julio pero, iniciada la Guerra Civil días después, se clausuró el certamen sin que los jurados de premios hubiesen podido emitir sus correspondientes

\footnotetext{
21. Vid nota 14.

22. Existe en el expediente del artista (Escuela de A. Aplicadas) un oficio del director dirigido al ministro de Instrucción Pública informando la petición del interesado.
} 
recompensas. Rico Cejudo, ya jubilado y en plena contienda, decide permanecer en Madrid intentando mantenerse con sus cuadros en aquel ambiente hostil, "eligiendo sus modelos entre los mesoneros y dueños de tascas -"El gato negro", "La Maison Doré", "Cervecería del Pasaje", etc.-, de esta manera se aseguraba el condumio diario, pero defendiendo sus obras con postura y dignidad" ${ }^{23}$. En estas circunstancias, el pintor cae enfermo aquejado de una afección renal lo que le obligó a permanecer internado en el sanatorio del Dr. Tapia durante cinco meses. La convalecencia y los efectos de la guerra, con la capital cercada y aislada, le obligan a permanecer en Madrid hasta 1939, en que regresa a Sevilla, enfermo aún, arruinado y olvidado por casi todos. Se instala en calle Alhóndiga, 14, y pronto, dado su carácter sociable y abierto, desea entrar en contacto con sus amigos y compañeros de los que permaneció alejado varios años. En carta fechada en Sevilla en 27 de abril de 1939 dirigida a Manuel González Santos, pintor y compañero de la Escuela durante muchos años, manifiesta entre otras cosas su delicado estado de salud que le impide "hacer la presentación oficial"; el encontrarse muy satisfecho por estar "al lado de mi hija -se refiere a Ana- y en mi Sevilla de mi alma"; así como los sufrimientos padecidos "moral y materialmente" en Madrid desde junio de $1936^{24}$.

Meses después, en 25 de octubre de 1939, a las 9 horas, fallece en su domicilio de Sevilla a los 75 años de edad, tras agudizársele la enfermedad que padecía y como consecuencia de un cáncer de próstata. Viudo de Carmen Simón Viso, dejaba dos hijos, José y Ana ${ }^{25}$.

23. Vid nota 16

24. La carta se encuentra en el expediente académico y profesional del pintor ya mencionado y dice textualmente:

“José Calvo Rocha, droguería, Alhóndiga n." 14. Sevilla.

Sevilla 27 de abril de 1939. Sr. Don Manuel González Santos.

Mi querido amigo: Como es de virtud he querido hacer la presentación oficial que acompaña a esta y desgraciadamente no he podido pasar a visitarle personalmente por encontrarme bastante fastidiado con la enfermedad de la orina que en Madrid se me agudizó y me obligó a estar durante los últimos cinco meses en el sanatorio del Dr. Tapia, donde si no me puse mejor, al menos estaba bastante bien atendido dado lo mal que se vivía en Madrid en cuestión de medicamentos y asistencias. Todavía, mi querido amigo, me parece un sueño encontrarme al lado de mi hija y en mi Sevilla de mi alma. Siempre me gustó Madrid para una temporada pero creo que si todavía me tuviese Dios en el mundo veinte años no volvería más a visitar la Corte según lo padecido en ella moral y materialmente desde junio del año 36 .

Al visitar la Escuela me enteré de que Vd. también se encuentra mal de la misma enfermedad lo que deploro con toda mi alma, deseándole se mejore lo antes posible. Cuando nos veamos cambiaremos impresiones sobre todo lo pasado y entretanto le ruego salude a sus hijos en mi nombre y Vd. reciba un abrazo de su verdadero amigo, José Rico Cejudo."

25. Todo ello consta en la correspondiente partida de defunción fechada en 26 de octubre, en la que se anota con evidente error que era natural de Carmona; así como que las diligencias se practican en virtud de manifestación de Amador Fariñas Noboa, mayor de edad, domiciliado en Alfonso XII, 2, como encargado para ello. Actuaron de testigo José Rojas Ligero y Antonio Navarro Adalia, "mayores de edad y vecinos de esta ciudad". Registro Civil de Sevilla, Distrito San Vicente. Libro de Defunciones de 1939, p. 221, n. 696. 
De esta manera, en el lecho del dolor, cuenta Antonio Illanes que le vio por última vez: "Yacía con un libro en las manos: "Arte y artistas flamencos", de Fernando el de Triana ${ }^{26}$.

Rico Cejudo fue, según Mattoni, "el pintor de la alegría y del movimiento, chispeante, decidor y travieso", y sus cuadros, al decir también de su paisano, "huelen a manzanilla fina" ${ }^{27}$.

26. Este libro editado en Madrid en 1935 y al que aportó su colaboración Rico Cejudo, se ha reeditado posteriormente en facsímil.

27. "Sevilla en sus pintores", en "Quien no vio Sevilla...". Sevilla, 1920, p. 143. 


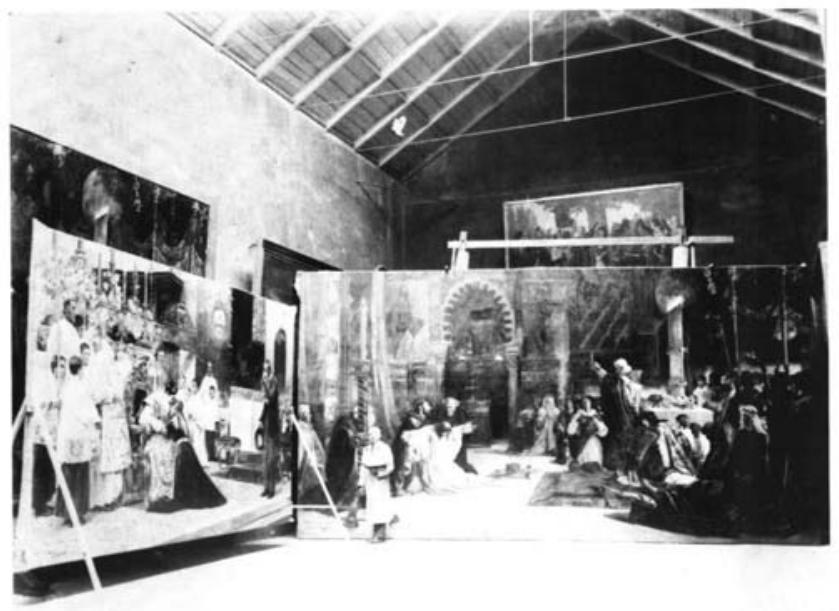

El pintor Rico Cejudo copiando en su estudio los cuadros: "Las postrimerias de San Femando", de Virgilio Mattoni, y "La primera Misa", de Alcázar Tejedor.

(Foto: Laboratorio de Arte de la Universidad de Sevilla.) 